\title{
A Case Study on Students' Application of Chemical Concepts and Use of Arguments in Teaching on the Sustainability-Oriented Chemistry Issue of Pesticides Use Under Inclusion of Different Scientific Worldviews
}

\author{
Robby Zidny ${ }^{1,2^{*}}$, Ayu Ningtias Laraswati ${ }^{3}$, Ingo Eilks ${ }^{1 * *}$ \\ ${ }^{1}$ Department of Biology and Chemistry, Institute for Science Education, University of Bremen, 28359 Bremen, GERMANY \\ 2 Department of Chemistry Education, Faculty of Teacher Training and Education, University of Sultan Ageng Tirtayasa, 42117 \\ Serang, INDONESIA \\ ${ }^{3}$ Madrasah Aliyah Negeri 2 Kota Serang, Indonesian Ministry of Religious Affairs, Serang, INDONESIA
}

Received 16 April 2021 - Accepted 4 June 2021

\begin{abstract}
The aim of this case study was to explore students' application of chemical concepts and their use of arguments in an educational research framework to incorporate and reconstruct indigenous science in chemistry education. This framework fosters education for sustainable development (ESD) in chemistry learning by integrating intercultural and multi-perspective scientific worldviews borrowed from indigenous and Western modern science. A socio-scientific issues-based, sustainability-oriented pedagogical approach was employed in a chemistry teaching intervention. Worksheet tasks, videos and an article were used in an inquiry-based teaching module in secondary $(\mathrm{N}=40)$ and tertiary $(\mathrm{N}=73)$ Indonesian chemistry education classes. Student responses to the worksheet questions were analyzed using qualitative content analysis. The results indicate that university students showed a better understanding of the chemical concepts compared to upper secondary school students. In terms of argumentation, both groups of students were able to broaden their spectrum of arguments, especially in the area of ethical arguments.
\end{abstract}

Keywords: chemistry education, chemical concepts, argumentation, education for sustainable development, multiple worldviews

\section{INTRODUCTION}

In recent years, the development of learning designs promoting education for sustainable development (ESD) in chemistry and science education has begun in some Western countries. New pedagogical approaches for chemistry ESD have been developed in several countries, e.g., plastics and their evaluation (Burmeister \& Eilks, 2012), life-cycle analysis (Juntunen \& Aksela, 2014b), and hydraulic fracturing (Zowada et al., 2018). The implementation of ESD in chemistry education is inherent to socio-scientific issues (SSIs) (Burmeister et al., 2012). SSI-based education has the potential to play a significant role in developing students' argumentation, decision-making, and informal reasoning skills (Sadler, 2004). These skills are crucial in fostering learners' scientific literacy level and in helping them better integrate their knowledge holistically in order to contemplate controversial scientific issues and dilemmas (Liu et al., 2011).

The movement towards ESD-based approaches by SSIs in chemistry learning has thus far been dominated by Western modern science (WMSc) worldviews. The role of environmental technology in solving environmental problems is one of the central focal points. Cultural and philosophical components have not been widely integrated into science education in general (e.g., Ideland, 2018; Khaddoor et al., 2017) and in relation to ESD in chemistry education in particular (Zidny et al., 2020). It is, however, that contexts and issues addressed by ESD vary depending on the culture, geographical conditions and the level of development of each country or community (Wiyarsi \& Çalik, 2019). Providing local cultural perspectives may affect chemistry teaching and

(c) 2021 by the authors; licensee Modestum. This article is an open access article distributed under the terms and conditions of the Creative Commons Attribution License (http://creativecommons.org/licenses/by/4.0/). 


\section{Contribution to the literature}

- This study investigates secondary and tertiary students' application of chemical concepts and use of arguments in sustainability-oriented chemistry education integrating different scientific worldviews.

- The findings have potential to contribute to ESD in chemistry education with the support indigenous science and culture as new perspectives.

- It is suggested that the inclusion of multiple scientific worldviews in chemistry education has potential to improve the level of students' arguments and facilitate them to connect chemical with socio-scientific, cultural and philosophical aspects.

learning when it tackles the challenge of sustainability. This is even more relevant in countries where different cultural perspectives, values, and worldviews exist in parallel. This is the case in countries with diverse indigenous communities such as Indonesia. We suggest that a reorientation of ESD would allow educators to better integrate interdisciplinary and multi-perspective worldview thinking into their teaching. This way might also include education for responsible citizenship and better the inclusion of diverse philosophical-cultural values (Eilks et al., 2013; Simonneaux, 2014; Sjöström et al., 2016; Zidny et al., 2020).

In this study, we suggest that providing multiple perspectives on scientific knowledge from indigenous knowledge (IK) and Western modern science (WMSc) can provide a valuable relationship between sustainability-oriented SSIs, cultural values and the relevance of science learning (Murray, 2015; Stuckey et al., 2013; Zidny et al., 2020). This relationship is suggested to be promising for ESD in terms of promoting systems thinking and decision making skills, and to reflect sustainability-oriented SSIs more holistically (Lee \& Grace, 2012; Sadler, 2004). Accordingly, combining multiple perspectives and SSI-based education can aid the students to develop ESD skills that are necessary to achieve critical scientific and technological literacy. Such approaches need to integrate scientific knowledge, knowledge about the context and sustainability debate, and argumentation across disciplinary boundaries including different scientific worldviews. In addition, dealing with alternative perspectives from IK can help students to better reflect also views on the nature and science based in WMSc. This can facilitate science education to foster better-balanced and more holistic worldviews and intercultural understanding (Zidny et al., 2020).

A recent study in Indonesian secondary and higher chemistry classes investigated various integration perspectives combining indigenous and WMSc. The study involved a teaching intervention on the topic of pesticides use in a multi-perspective science worldview approach combining IK and WMSc. The study received positive feedback from the students (Zidny \& Eilks, 2020). Learners viewed the lesson as both interesting and relevant to them. They thought that it fostered their insights into how chemistry learning should be interconnected with other scientific worldviews and cultures to find solutions to sustainability issues. More research is needed to identify how teaching interventions based on multiple worldviews effect the ESD skills necessary to develop critical, eco-reflexive scientific and technological literacy, especially related to the ability of the application of chemical concepts and use of arguments (Sjöström et al., 2016; Sjöström \& Eilks, 2018). The current case study explores and analyses students' use of chemical concepts and arguments when dealing with a sustainability issue connected to indigenous science (ISc).

\section{THEORETICAL BACKGROUND}

\section{Different Perspectives on Scientific Worldviews}

According to the main orientations of scientific literacy, Roberts $(2007,2011)$ distinguished between two visions of scientific literacy. Vision I focuses on the learning of scientific content and processes for later application. Vision II emphasizes understanding the usefulness of scientific knowledge, beginning with everyday life and societal contexts. Recently, Sjöström and Eilks (2018) suggested a more advanced vision of science literacy, which they called Vision III. Vision III focuses on transdisciplinarity, philosophical values and critical practice with respect to the application and effects of science and technology in society. The implication of Vision III is a reconsideration of the contents and contexts of science education to incorporate societal perspectives and controversial, authentic and relevant SSIs into itself (Hofstein et al., 2011). Based on Vision III, educators should consider multifaceted cultural perspectives in terms of the norms, values and worldviews in any corresponding society when they select and teach certain content matter (Sjöström \& Eilks, 2018). Multifaceted cultural perspectives should integrate and contrast WMSc with other cultural identities, including but not limited to Eastern cultural perspectives, alternative Western philosophies, and IK (Zidny et al., 2020).

From this point of view, science educators and teachers have designed new curricula that represent a more balanced perspective by introducing students to multiple ways of understanding science (Snively \& Williams, 2016). Indigenous perspectives may provide 


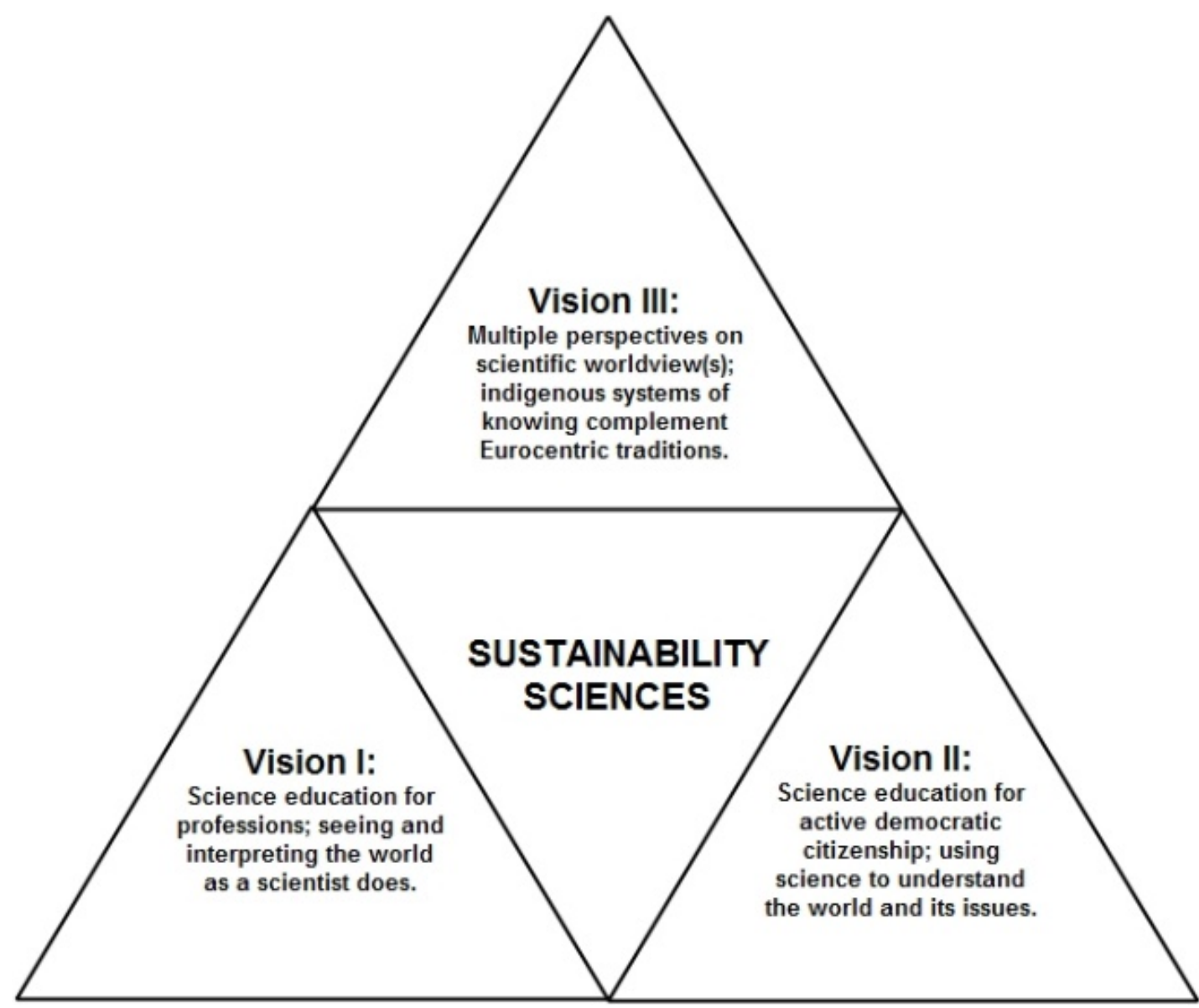

Figure 1. The three visions of science education with sustainability science as the foundation (Murray, 2015)

insight and guidance into environmental ethics when it comes to solving complex societal problems in order to achieve sustainability. IK is inherited orally from ancestors and makes up various forms of ISc. This knowledge is potentially interesting and personally relevant to students from the corresponding society. Accordingly, learning about ISc may help students to recognize the intimate connection between humans and nature in local and global cultural environments. Murray (2015) suggested three dimensions for the foundation of science education with sustainability. According to this model, science education has to recognize sustainability sciences, the research fields that deal with sustainability including a balanced view on how society affects the physical environment and how the state of the physical environment affects society (Snively \& Williams 2016; Murray 2015). Concerning with sustainability sciences in science education according to this model suggests science education not merely to focus on the environment, but also to recognize science education's contribution to citizenship education and understanding cultural contexts. This aspect is critical for understanding the interrelationship between science, sustainability, socio-scientific issues, and the relevance of science (Murray 2015). In Murray's diagram (Figure 1), the term Vision III includes multiple perspectives on scientific worldviews, including IK systems which complement WMSc. This is in line with the Vision III of scientific literacy proposed by Sjöström and Eilks (2018) emphasizing the critical component of scientific literacy for responsible citizenry. This has important implications for the science and chemistry curriculum. It suggests to incorporate societal and, where relevant, indigenous perspectives into science education. Dealing with sustainability sciences according to Murray's diagram can be understood as a trigger to integrate multiple worldviews in the science curriculum to raise the relevance of science education in its three dimensions, namely individual, societal, and vocational relevance (Stuckey et al., 2013). In this case, ISc might serve as a source for socio-scientific and cultural issues to promote the relevance of science education.

\section{An Educational Design Framework to Integrate Multiple Perspectives on Scientific Worldviews}

An educational design framework was used to introduce ISc as both content and context into chemistry education (Zidny et al., 2020). The framework in Figure 2 was adapted from the Model of Educational Reconstruction (MER) (Duit et al., 2005). This approach links the analysis of science content structure to both research on teaching and learning and to the development of instruction. In this study, the ideas behind the MER were used as an educational framework 


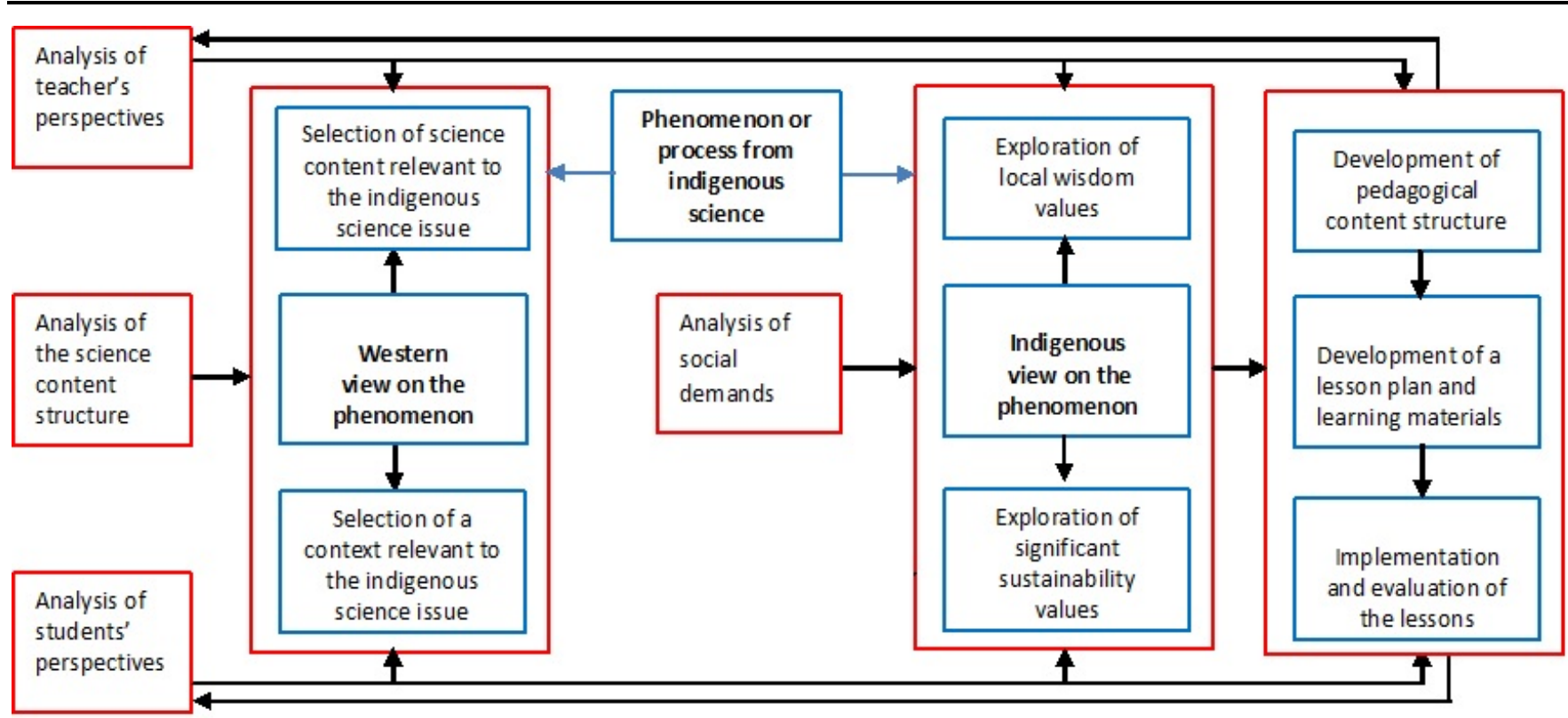

Figure 2. Educational design framework to incorporate ISc into science education (Zidny et al., 2020)

suggesting to reconstruct aspects of alternative views and understandings of science (here ISc) and to compare them to WMSc. This is done in order to identify content and to develop contexts for science instruction that meet students' perspectives, abilities, and needs. The inclusion of ISc in science education through educational reconstruction helped to develop a more complex representation of ISc for science education, including aspects of societal, environmental, and idiosyncratic contexts in order to demonstrate their importance for the individuals' life in society (Zidny et al., 2020). The MER also suggests to take the interdisciplinary nature of relevant science education into account when conducting science education research and development. In this study, the MER served as a base for developing a model for research-based curriculum development focusing ISc relevant of science education (Figure 2). The idea of multiple perspectives on scientific worldviews was integrated to provide a stronger connection between ISc and WMSc, sustainability issues, cultural values and the relevance of science learning (Murray, 2015; Zidny et al., 2020).

Pedagogical elements such as interdisciplinarity and argumentation are suggested to represent the socioconstructivist and critical components found in advanced ESD (Juntunen \& Aksela, 2014a). According to the framework, it is suggested to analyze the students' perspectives in terms of their views, concepts, and arguments about scientific phenomena formed by the two different knowledge systems (ISc and WMSc) as well as about how these multiple worldviews help developing solutions to sustainability issues.

\section{Application of Chemical Concepts and Argumentation}

The aim of Vision I and II of scientific literacy according to Roberts (2007) is the application of scientific content knowledge to understand everyday life situations. Accordingly, students' ability to connect science content to real-life socio-scientific issues needs to be developed. However, other skills are needed beyond the mere accumulation of knowledge. The literature suggests that problem solving, argumentation and decision-making skills belong in this tool kit (Broman \& Parchmann, 2014; Dori et al., 2003; Zohar, 2004; Zohar \& Dori, 2003).

The field of argumentation is considered especially important when it comes to dealing with SSIs in the science classroom (Erduran et al., 2015; Sadler, 2004; Sadler \& Zeidler, 2005). Several studies have indicated that a relationship between scientific epistemological views and reasoning in socio-scientific issues exists (Liu et al., 2011). A further implication is that students' argumentation skills are probably influenced by their epistemological beliefs. This is because these beliefs are the source of skepticism and criticism about different knowledge claims found in SSIs. Accordingly, multidisciplinary and multi-perspective thinking is necessary in learning science in order to foster learners' argumentation skills about complex SSIs (Karpudewan \& Roth, 2018; Lee \& Grace, 2012; Rundgren et al., 2016). Such thinking aspects can contribute to students' openmindedness, their understanding of controversial SSIs, their bias identification skills, and their critical refection skills when dealing with SSIs (Oulton et al., 2004).

Argumentation in this study refers to any arguments and informal reasoning. This includes claims, data and justifications which may be supported by evidence, modal qualifiers or rebuttals (Erduran et al., 2004; Sadler, 2004). This view of argumentation is important, especially when an SSI is open-ended, debatable, and complex, provides no definitive answers, and is 


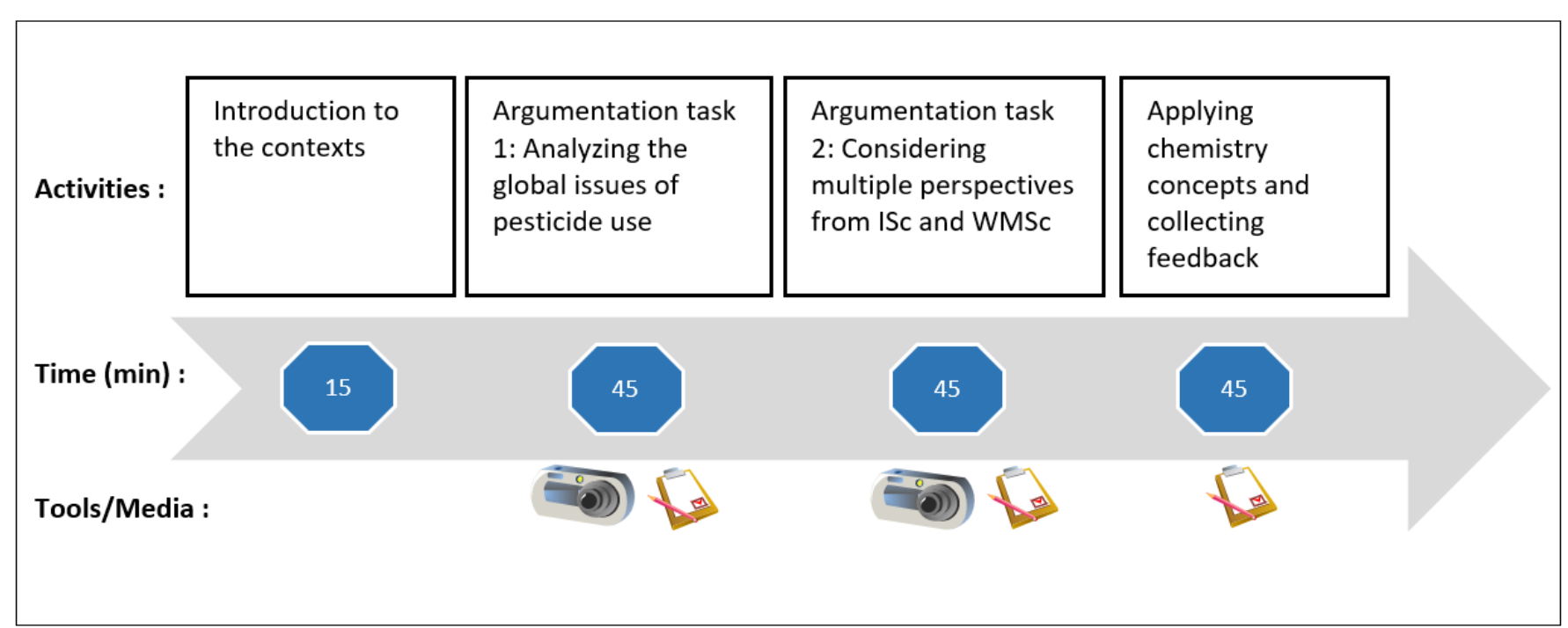

Figure 3. The design of the teaching intervention

Table 1. Discussion questions on the global issues of the pesticides use ("Argumentation task 1") Q1 : Perception about global issues of the potential risk of pesticides

Synthetic pesticides have improved over time and are currently regulated by strict safety standards, but they still have the potential to pollute soil and water, impact wildlife, and even harm us. Moreover, they also lead to the rise of "superbugs" which are resistant to different insecticides.

a. Considering all these risks, do we really need pesticides? Please explain your reason.

b. How do you suggest resolving or addressing the potential risk of pesticides?

influenced by multiple perspectives, beliefs and moral judgments (Lee \& Grace, 2012; Sadler, 2004).

\section{Focus of the Study and Research Questions}

This case focuses students' use of chemical concepts and arguments about pesticides use from the perspective of both WMSc and ISc. The arguments were analyzed to describe the students' stance on the issue, which is an essential part of a socio-constructivist approach to ESD (Juntunen \& Aksela, 2014a; Marks \& Eilks, 2009). The teaching intervention involved two sections of students' debate in order to analyze the effect of the multiperspective approach on the arguments the learners apply in the lesson. Problem-solving in a related context was also investigated to see if the students could connect chemical concepts with a real-world problem found in society. The analysis was conducted to answer the following questions: 1 ) How do students apply chemical concepts to pesticides use based on the approach specifically selected for this study? and 2) What level of arguments do the learners apply in the context of pesticides use when being taught with a multiperspective approach?

\section{METHOD}

\section{Teaching Intervention}

The teaching intervention was conducted in a total of two and a half hours. It compared common modern chemistry approaches to alternative green pesticides found in ISc. Multiple perspectives were offered, including the views of WMSc and ISc. Several worksheet tasks were used to promote conceptual understanding and argumentation skills among the learners. Three worksheets were introduced which engaged the learners in a discussion based on watching two videos and reading an article on the topic (Figure 3 ).

In the beginning, the students engaged in a discussion about their general understanding of pesticides use and green pesticides. This session explored the prior knowledge of the participants and linked their perceptions to the current sustainability SSI of pesticides use. After this, students watched a video from TEDx (by Fernan Pérez-Gálvez) entitled "Do we really need pesticides?" (https://ed.ted.com/lessons/ do-we-really-need-pesticides-fernan-perez-galvez\#

watch). This activity led to a brainstorming exercise in which the participants identified the various aspects surrounding the common synthetic pesticides used worldwide. It also emphasized the role of scientific technology (in the sense of WMSc) in order to overcome the problems of synthetic pesticides use. The students were asked to make a decision based on arguments presented by worksheet 1 (Table 1) and to participate in a pro and con group debate. The teacher guided the groups in exploring their arguments through both an interview and class discussion.

In the next section, discussion of the issue based on multiple scientific worldviews was initiated. Alternative views borrowed from ISc in the local area were introduced. Then they were contrasted with 


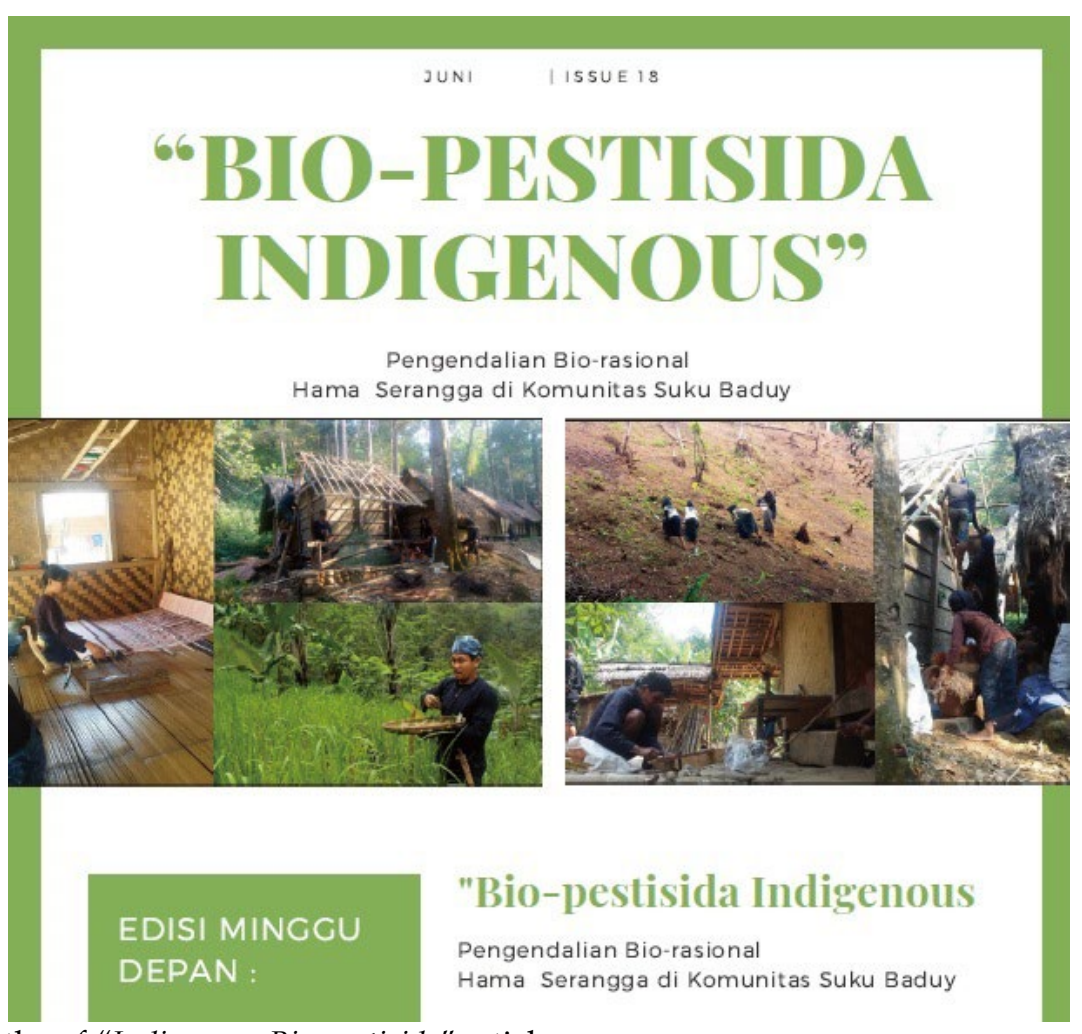

Figure 4. Front cover of the of "Indigenous Bio-pesticide" article

Table 2. Discussion questions on multiple worldviews on the issue of pesticides use ("Argumentation task 2")

Q2 : Perception about the multiple perspective worldview on the sustainability issues of pesticides

Today, scientists search for alternative bio-rational pest control strategies that balance the demands of food production with environmental concerns. Indigenous knowledge could become a source of inspiration for Western science to develop sustainable agriculture. For instance, the Baduy community in Indonesia have unique knowledge and traditions to control pest insects. They use integrated pest management and utilize natural pesticides extracted from local plants as insect repellent.

a. Can indigenous bio-pesticides become the future of green pesticides? Please analyze the pros and cons of using natural pesticides from local plants as an alternative to synthetic pesticides.

b. The Baduy people view nature in an integrated worldview with respect for all living things. They use bio-pesticides not to kill the insects, but to repel them. The natural balance is maintained and environmental pollution avoided. Should we consider the perspective of indigenous people to add insight and guidance to the environmental view in Western modern science? Please explain your arguments.

developments in WMSc in order to possibly resolve the issue. A video about natural pesticide use by the Baduy tribe, an indigenous community in Indonesia, and an article entitled "Indigenous bio-pesticide: Bio-rational control of pest insects in the Baduy community" were provided (Figure 4). The video and article explain the Baduy's agricultural system, their cultural values and philosophies about conserving nature, as well as their use of indigenous bio-pesticides. The article emphasizes how the Baduy maintain their culture and philosophy to preserve nature. The Baduy have a philosophy called pikukuh. This states: “...gunung teu meunang dilebur, lebak teu meunang diruksak, lojor teu meunang dipotong, pondok teu meunang disambung..." ("...the mountain is not allowed to be destroyed, the river is not allowed to be destroyed. If it is long, it is not allowed to be cut and if it is short, it is not allowed to be connected..."). The essence of the Baduy's philosophy means that humans should respect nature. They are not allowed to change anything that could cause damage to the environment.

The second worksheet (Table 2) asks the students to discuss the alternative solution from the ISc perspective, which offers the sustainability approach of using green pesticides from plant extracts. The participants analyzed the risks and benefits of using natural (green) pesticides derived from local plants. Then the teacher guided them through a class discussion on their arguments.

At the end of the session, participants were asked to apply chemistry concepts in order to explain sustainability issues of pesticides and the phenomena or processes from ISc based on the third worksheet (Table 3 ). The intervention was adjusted in terms of theoretical depth to both the upper secondary school chemistry curriculum and the general chemistry level at the university. 
Table 3. The chemistry problem-solving task

Q3 : Applying chemistry concepts about the related context

1. DDT (Dichlorodiphenyltrichloroethane) is a synthetic insecticide belonging to the family of organic halogenated compounds. Although it was very useful, it is resistant to environmental degradation because of great stability. DDT also can be accumulated in the fatty tissues of living organisms for long periods of time and exhibit toxicity.

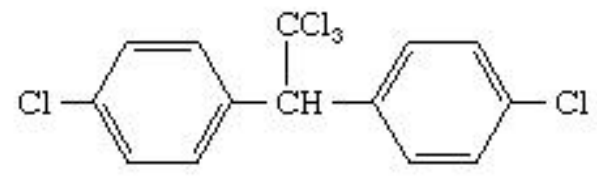

DDT

a. In your understanding, what makes DDT resistant to environmental degradation? Please give an explanation (connected with chemical structure and stability).

b. In your understanding, what causes DDT can be accumulated in the fatty tissues of living organisms and exhibit toxicity? Please give your explanation (connected with chemical structure and solubility).

2. Indigenous knowledge of bio-rational control of pest insects could be used as an alternative to synthetic pesticides. The Baduy community located in Banten (Indonesia) uses plants as natural pesticides to protect their crop (read the article). Please give your scientific explanation regarding the phenomena/ process of the indigenous people to answer the following questions:

a. The Baduy community uses natural pesticides from local plants to protect their rice crops. Some plants contain secondary metabolite compounds which exhibit "strong scent" to repel pest insects. In your understanding, what functional groups are responsible for those properties?

b. To manufacture their crude extract of natural/botanical pesticides, the Baduy people use fermented palm sugar juice. What compounds might be formed from these solvents? Please give an explanation.

c. Please predict what kind of chemical compounds (based on polarity) can be extracted using those solvents? Please give an explanation.

d. In your understanding, how do chemists identify and analyze bio-active compounds in plants? Please explain the process.

\section{Sample}

The total number of participants were from two classes of first-year university chemistry student teachers $(\mathrm{N}=73)$ and two classes of upper secondary school students $\left(12^{\text {th }}\right.$ grade, science major $)$ in Indonesia $(\mathrm{N}=40)$. The study looked at two different levels to compare the effects of the intervention at different educational phases in order to better understand what happens when developing teaching and learning designs for different educational levels. Both groups learned at institutions which are geographically near the Baduy community. The cultural background of the students was diverse. Some learners lived in rural areas near indigenous environments, but did not live indigenous lifestyles. Most of the students had contact with IK in their daily lives, but had been primarily influenced by the majority culture of contemporary Indonesian society.

\section{Data Collection}

A total of three worksheets were used in this study. The first worksheet was used to explore students' arguments on the issue of pesticides use based on modern chemistry (Table 1). The second worksheet (Table 2) employs arguments which consider an additional perspective borrowed from ISc. The third worksheet (Table 3) was used to assess the learners' ability to apply chemistry concepts to the pesticides use issue. Each person voluntarily took part in the study. All official Indonesian regulations for carrying out studies with human beings in educational settings were respected.

\section{Data Analysis}

The student questionnaires were analyzed using qualitative content analysis (Mayring, 2000). Categorization of the responses to the worksheets was conducted based on the classification presented in Table 4. Worksheets 1 and 2 (Tables 1 and 2) answers were categorized based on Liu et al. (2011). The arguments were classified either as socio-economic, ethical, ecological or scientific. The analysis did not emphasize the quality of the students' argumentation. Rather we sought to discover how students relate arguments by analyzing aspects of a sustainability issue. The arguments expressed in the first and second argumentation task were analyzed in terms of where they fit into the four categories. Key concepts and examples for each category are presented in Table 5. Students' responses to chemical problem-solving in worksheet 3 (Table 3) were analyzed using four modified categories taken from Akkuzu and Uyulgan (2016), and Broman and Parchmann (2014). An explanation of these categories is also provided in Table 4. 
Table 4. Categorization of student answers based on their argumentation and application of chemical concepts

\begin{tabular}{|c|c|c|}
\hline No & Worksheet Questionnaire & Category of answer \\
\hline Q1 & $\begin{array}{l}\text { Student's argumentation on the issue of } \\
\text { potential risks of pesticides use }\end{array}$ & $\begin{array}{l}\text { Students' arguments was categorized as: } \\
\text { - socio-economic }\end{array}$ \\
\hline Q2 & $\begin{array}{l}\text { Student's argumentation on the multiple } \\
\text { perspectives of scientific worldviews from } \\
\text { WMSc and ISc }\end{array}$ & $\begin{array}{l}\text { - } \text { ethical, } \\
\text { - } \text { ecological } \\
\text { - } \text { scientific } \\
\text { The categorization was adopted from (Liu et al., 2011) }\end{array}$ \\
\hline Q3 & $\begin{array}{l}\text { Applying chemistry concepts in a related } \\
\text { context }\end{array}$ & $\begin{array}{l}\text { The student's response was categorized as: } \\
\text { - C1: Student answered the task by connecting a chemistry concept } \\
\text { to the context } \\
\text { - C2: Student answered the task using an inappropriate chemistry } \\
\text { concept as explanation or has misconceptions for the context } \\
\text { - C3: Student answered the task by repeating the question } \\
\text { - C4: Student was unable to answer the question / no response } \\
\text { The categorization was modified from (Akkuzu \& Uyulgan, 2016; } \\
\text { Broman \& Parchmann, 2014) }\end{array}$ \\
\hline
\end{tabular}

Table 5. Student argument classifications and illustrative examples

\begin{tabular}{|c|c|c|}
\hline Categories & Key concepts & Illustrative examples \\
\hline Socio-economic & $\begin{array}{l}\text { Economic } \\
\text { development, cost or benefits } \\
\text { to a person or society (e.g, in } \\
\text { the form of gains) }\end{array}$ & $\begin{array}{l}\text { "From an economic standpoint, indigenous pesticides (natural } \\
\text { pesticides) are easier to obtain and you do not need to spend a lot } \\
\text { of money." } \\
\text { "Synthetic pesticides are still needed, especially for basic crops that } \\
\text { support people's lives, despite all the health risks they cause." }\end{array}$ \\
\hline Ethical & $\begin{array}{l}\text { Values or personal opinion } \\
\text { related to aesthetics or the } \\
\text { future, environmental ethics } \\
\text { (e.g, What is right What is } \\
\text { wrong? What should be } \\
\text { done?) }\end{array}$ & $\begin{array}{l}\text { "The most important value in life is to be happy and sustainable." } \\
\text { "We must pay attention to environmental ethics so that future } \\
\text { knowledge does not deviate from natural law." } \\
\text { "Indigenous knowledge is based on mutually agreed upon } \\
\text { principles and norms. Indigenous people have a philosophy to } \\
\text { preserve nature." }\end{array}$ \\
\hline Ecological & $\begin{array}{l}\text { Effect on the environment or } \\
\text { ecosystem and human } \\
\text { ecological action (e.g, eco- } \\
\text { friendly products) }\end{array}$ & $\begin{array}{l}\text { "The advantage of using natural pesticides is that they can repel } \\
\text { insect pests from plants without poisoning and damaging the } \\
\text { environment." } \\
\text { "We must limit the use of synthetic pesticides that can damage the } \\
\text { ecosystem or food chains that exist." }\end{array}$ \\
\hline Scientific & $\begin{array}{l}\text { Natural resources, } \\
\text { technologies, evaluation of } \\
\text { risk and safety }\end{array}$ & $\begin{array}{l}\text { "Natural pesticides are not durable enough to protect plants from } \\
\text { pests for long because they evaporate faster". } \\
\text { "Combining indigenous knowledge and technology can lead to } \\
\text { extraordinary new innovations." }\end{array}$ \\
\hline
\end{tabular}

The categorization of all data took place in two rounds carried out by two raters with expertise in chemistry education (R.Z. and A.N.L.). Any disagreements were solved through negotiation. The score of the final inter-rater reliability was high, with the Cohen's kappa score of $\mathrm{k}=0.923$ for the analysis of the students' application of chemical concepts and $\mathrm{k}=0.968$ for the analysis of the students' arguments.

\section{FINDINGS AND DISCUSSION}

\section{Students' Application of Chemistry Concepts in the Final Problem-Solving Task}

The percentage distribution of the students' answers in the categories from Table 4 are shown in Table 6.
The results show that the average number of responses of undergraduate students to the problemsolving task (column C1) was greater than among secondary high school learners. Undergraduate students used more chemistry concepts to answer the problemsolving task as compared to secondary school participants. There was, however, quite a number of students who were unable to apply any chemical concepts to the context presented in the problem-solving task.

To explore how students applied chemistry concepts when answering the problem-solving task, the analysis looked deeper into the responses coded C1 and C2. For task 1a, most of the correct responses from both groups made a connection between the structure of matter, organic chemistry and chemical bonding. The students suggested that the stability of DDT structure is affected 
Table 6. Distribution of student answers based on the categories

\begin{tabular}{|c|c|c|c|c|c|c|c|c|}
\hline \multirow{2}{*}{$\begin{array}{l}\text { Problem Solving } \\
\text { Chemistry (Q3) }\end{array}$} & \multicolumn{4}{|c|}{$\begin{array}{c}\text { Undergraduate student's response in each } \\
\text { category }(\%)\end{array}$} & \multicolumn{4}{|c|}{$\begin{array}{c}\text { Secondary school student's response in each } \\
\text { category }(\%)\end{array}$} \\
\hline & C1 & $\mathrm{C} 2$ & C3 & C4 & C1 & $\mathrm{C} 2$ & C3 & $\mathrm{C} 4$ \\
\hline $1 \mathrm{a}$ & 80.8 & 6.9 & 9.6 & 2.7 & 65.0 & 7.5 & 27.5 & 0.0 \\
\hline $1 b$ & 37.0 & 9.6 & 30.1 & 23.3 & 25.0 & 2.5 & 60.0 & 12.5 \\
\hline $2 a$ & 75.3 & 0 & 13.7 & 11.0 & 27.5 & 0 & 30.0 & 42.5 \\
\hline $2 b$ & 38.3 & 1.4 & 17.8 & 42.5 & 27.5 & 0 & 22.5 & 50 \\
\hline $2 c$ & 26.0 & 0 & 23.3 & 50.7 & 5 & 2.5 & 17.5 & 75 \\
\hline $2 d$ & 28.8 & 1.4 & 35.6 & 34.2 & 5 & 0 & 35 & 60 \\
\hline
\end{tabular}

by the benzene functional group. For example, one person stated that "DDT is resistant to degradation because it contains the benzene structure that is very stable." However, this type of answer tends to use factual knowledge only to answer the task. The learners remembered that the presence of a benzene structure can make molecules quite stable. Whether these students could give the real reason for the relative stability of the benzene structure (electron delocalization) remains unclear. More complete answers for Task 1a were given by most of the university students. For example: "From its structure, the DDT compound is very stable because it consists of two benzene rings which can undergo electron delocalization. The process of decomposing the compound is very difficult and requires great amounts of energy to separate the bonds." In this type of response, students showed a deeper understanding by connecting the concepts of a benzene molecular structure with electron delocalization and considering aspects of chemical thermodynamics. The concept of "structure resonance" which is caused by oscillating double bonds in the benzene ring was also found in many university student answers. An interesting answer from one secondary school student attempted to provide a personal explanation of the benzene structure: "Benzene has strong bonds. These are difficult to break down because the electrons are back and forth around the ring." Nevertheless, more advanced explanations which explain the stability of the structure by looking at halogen atom (chlorine) substitution were not found in either of the groups. This is not surprising, since the effects of substituent groups in benzene compounds are only taught in the second year of university chemistry in Indonesia.

In task $1 \mathrm{~b}$, the problem-solving question also focused on the structure of matter, chemical bonding and organic chemistry. The chemical concepts used by both groups of students included solubility, polarity, and hydrophobicity. In both groups, many of the responses linked the solubility to its polarity by using the principle "like dissolves like". As one student mentioned: "DDT can be accumulated in fatty tissue due to its non-polar properties. According to the principle of "like dissolves like", DDT will dissolve in fatty tissue (non-polar)." In addition, most of the upper secondary school students emphasized the connection between the benzene structure in DDT with its solubility, which their answers depicted: "In DDT, there is a benzene structure, which is non-polar, just like human fatty tissue. So when benzene compounds enter human fatty tissue, they will be equally soluble, because both are non-polar." This example shows that this person used the structural formula as a strategy to answer the question and combined it with recalled, memorized, factual knowledge. More of the university students were able to elaborate on the concepts of polarity, molecule structure, and hydrophobicity and tie them to solubility properties: "DDT is non-polar as indicated by the number of carbon atoms contained in two benzene groups. DDT is able to interact with the fat in nonpolar body tissues as well. DDT has difficulty reacting with water in the blood, because it is hydrophobic. This causes DDT to accumulate in fat and not be transported by the blood so that it cannot be excreted."

Task 2 is related to the content areas of the structure of matter, chemical bonding, organic chemistry, chemical reaction and chemical analysis. Most correct responses in both groups were able to apply the concept of organic functional groups to the physical properties of bio-pesticide compounds. The answers predicted that the "strong scent" insect repellent properties of secondary metabolite compounds in bio-pesticides was the result of common molecular functional groups in organic compounds which contain either ester groups or aromatic compounds. Some university students also mentioned essential oil structures in their responses, while secondary school students did not. The reason for this is that upper secondary school does not teach the concept of essential oils in the school curriculum. Furthermore, the students were asked to predict the chemical reaction creating the solvent (fermented palm sugar juice). They were also asked to identify the chemical properties of the solute compounds used in the extraction process of indigenous bio-pesticides. The answers mentioned the concepts of carbohydrates, fermentation reactions, alcohol and carboxylic groups, and the polarity of compounds. In both groups, students mentioned alcohol and carboxylate groups as the potential groups in the solvent based on sugar fermentation. The secondary school students were unable to explain the sugar fermentation reaction in symbolic representation. The university students were able to elaborate on more concepts in their answers. One student wrote: "Palm sugar juice usually contains carbohydrates, which can be broken down into glucose, sucrose and fructose. Glucose is converted to pyruvic acid in anaerobic 
Table 7. Common concepts used in student responses to the problem-solving questions (Q3)

\begin{tabular}{|c|c|c|c|}
\hline Number & Topic in problem-solving & Content area & Example of concepts \\
\hline 1 (a) & $\begin{array}{l}\text { The social issue of pesticides (a case } \\
\text { study on DDT) in the environment }\end{array}$ & $\begin{array}{l}\text { Structure of matter } \\
\text { Chemical bonding } \\
\text { Organic chemistry }\end{array}$ & $\begin{array}{l}\text { Stability of chemical structure, } \\
\text { benzene, aromatic compound electron } \\
\text { delocalization, bonding energy, } \\
\text { structure resonance }\end{array}$ \\
\hline $1(b)$ & $\begin{array}{l}\text { The issue of pesticides that endanger } \\
\text { human health }\end{array}$ & $\begin{array}{l}\text { Structure of matter } \\
\text { Chemical bonding } \\
\text { Organic chemistry }\end{array}$ & $\begin{array}{l}\text { Solubility, polarity, hydrophobic } \\
\text { molecule, like dissolve like, Benzene, } \\
\text { functional groups }\end{array}$ \\
\hline $2(a, b, c, d)$ & $\begin{array}{l}\text { How students explain chemical } \\
\text { phenomena from IS from a scientist's } \\
\text { point of view }\end{array}$ & $\begin{array}{l}\text { Structure of matter } \\
\text { Chemical bonding } \\
\text { Organic chemistry } \\
\text { Chemical reaction } \\
\text { Chemical analysis }\end{array}$ & $\begin{array}{l}\text { Functional groups, carbohydrates, } \\
\text { fermentation reaction, polarity, like } \\
\text { dissolve like principle, chemical } \\
\text { reagent, extraction }\end{array}$ \\
\hline
\end{tabular}

reaction and can produce alcohol (ethanol) under those conditions." Most university students were also able to predict that the compound extracted by these solvents must be a polar compound. They connected the concepts of the polarity of alcohols and the "like dissolves like" principle. One person mentioned that "the extract compounds probably contain the functional groups of alcohols, aldehydes, carboxylic acids, and esters. The reason is that these compounds have polar properties and can be extracted based on the "like dissolves like" principle." This task was more challenging for secondary school participants, because the structural formula of the compounds was not given as a clue. As a result, most of these students were unable to predict the nature of the solvent. They also had difficulty naming the kinds of potential chemical compounds (based on polarity) and the potential nature of compounds which are extractable using those solvents.

The last problem-solving task dealt with a chemical analysis of the bio-active compounds in plants. Both groups of learners showed limitations in their knowledge of analytical chemistry. Some of the university students were able to explain general techniques in natural products analysis. One student wrote: "The steps of the analysis are: taking a sample from the plant, selecting the appropriate reagents to test its compounds, separating or extracting bio-active compounds from the plant, and identifying the bio-active content." However, they were unable to mention details of the qualitative or quantitative analysis of organic compounds. They could not describe separating or purification techniques for natural products such as chromatography, steam distillation, solvent extraction, etc. According to the Indonesian upper secondary school curriculum, the area of analytics in organic chemistry is limited to qualitative analysis of organic compounds. Analysis focuses only on the qualitative identification of the alcohol, aldehyde, ether, ester, carboxylic acid, etc. functional groups. More advanced organic chemical techniques, like separating or purification techniques, are studied only at the university level.
In conclusion, both groups contained several students who were able to link the context and concepts (see Table 7). The upper secondary school students, however, tended to recall factual knowledge only. This indicates the dominance of the rote learning of chemical content knowledge. The university students were able to better elaborate a more constructive explanation of the tasks and to make better connections between the concepts. The most often-used ideas referred to molecular structure stability, solubility, polarity, the functional groups on organic compounds, aromatic compounds, the chemical and physical properties of organic compounds, and analytical chemistry. This indicates that these concepts are available to students at least to a certain extent - in order to understand the chemical problem in question. These concepts are closely related to the topics of general chemistry and organic chemistry, and the interplay between concepts within the topics is crucial (Duis, 2011).

Some misconceptions were also identified in the answers. Table 8 shows some of the statements which involve misconceptions. The most common misconception occurred when the learners tried to relate the concept of chemical structure stability to the concepts of hydrophobicity or the carbon chain length. For instance, one university student confused and misused the concept of hydrophobicity of a compound with its reactivity or stability: "Benzene (in DDT) is hydrophobic, so there is no water in the environment, so it is difficult to react." The student generalized water as a universal solvent in a chemical reaction. Interaction with water was considered crucial for reactivity or stability. Another student used an inappropriate explanation to connect structure stability to the carbon chain length, boiling point and energy of the reaction: "DDT is difficult to decompose because it has a large number of carbon atoms in the chain, which makes its boiling point higher, and requires more energy." In this example, the person misinterpreted the concept of chemical change (chemical degradation or reaction) as a physical change (the boiling process). This kind of misconception was also found among secondary school students: "DDT compounds contain benzene, which 
Table 8. Student quotes with misconceptions acquired from worksheets

Misconceptions of university students

Concepts

Misconception

Stability of chemical structure, Hydrophobicity,

Benzene

Stability of chemical structure, Carbon chain

length, boiling point, reaction energy

Benzene is hydrophobic. There is no water in the environment, so it is difficult to react.

DDT is difficult to decompose because it has a large number of carbon atoms on the chain, which makes its boiling point higher, and requires more energy.

Solubility, polarity, Halogen $(\mathrm{Cl})$ groups

DDT accumulates in fat due to the polarity of $\mathrm{CCl}_{3}$ groups.

Solubility, carbon-chain length, boiling point,

DDT structure has many $C$ atoms, causing the boiling point to be higher and making it difficult to dissolve in water.

Misconceptions of upper secondary school students

\section{Concepts}

Stability of chemical structure, halogen group,

electron configuration

Stability of chemical structure, Benzene, boiling point, evaporation

Solubility, lone pair electron, polarity, solvent

\section{Misconception}

DDT is difficult to degrade because it has halogen group compounds that have a full electron configuration

DDT compounds contain benzene, which is difficult to decompose because it is difficult to evaporate due to its high boiling point Compounds that have a lone electron like $\mathrm{Cl}$ can dissolve in a polar solvent.

DDT is very polar because it has a very electronegative $\mathrm{CCl}_{3}$ group.
It seems that this misconception led these students to falsely claim that DDT is polar and can dissolve in polar solvents due to the electronegativity of the halogen $(\mathrm{Cl}$ group) in the molecule. The students focused solely on the halogens groups $\left(\mathrm{CCl}_{3}\right)$ in the structure without considering the overall structure and geometry of the whole molecule. Similar results were reported previously by Akkuzu and Uyulgan (2016). These mistakes can also be tied to students struggling with the ideas of bonding, solubility and molecular polarity (Broman \& Parchmann, 2014; Reid \& Hassan, 2004). Furthermore, another misconception appeared when an upper secondary response linked the concepts of solubility, boiling point and carbon chain length: "DDT structure has many $C$ atoms, causing the boiling point to be higher, so it will be difficult to dissolve in water." It seems that some students confuse the size of the molecules and their boiling points of the compound with the concept of solubility.

\section{Student Arguments Related to the Context of the Pesticide Sustainability Issue in a Multi-Perspective Scientific Worldview Approach}

Figures 5 and 6 show that learners (in both groups) generally expressed more arguments in all categories in the Argumentation task 2 as compared to the Argumentation task 1. Both groups also shared a quite similar trend in the proportion of arguments in both first and second argumentation tasks. The discussion of the holistic approach in which WMSc and ISc are involved in resolving sustainability issues had an impact on the students' argumentation in all of the categories. The number of students' expressing socio-economic, ethical and ecological arguments increased, while the scientific arguments showed only a slight increase. Ecological 


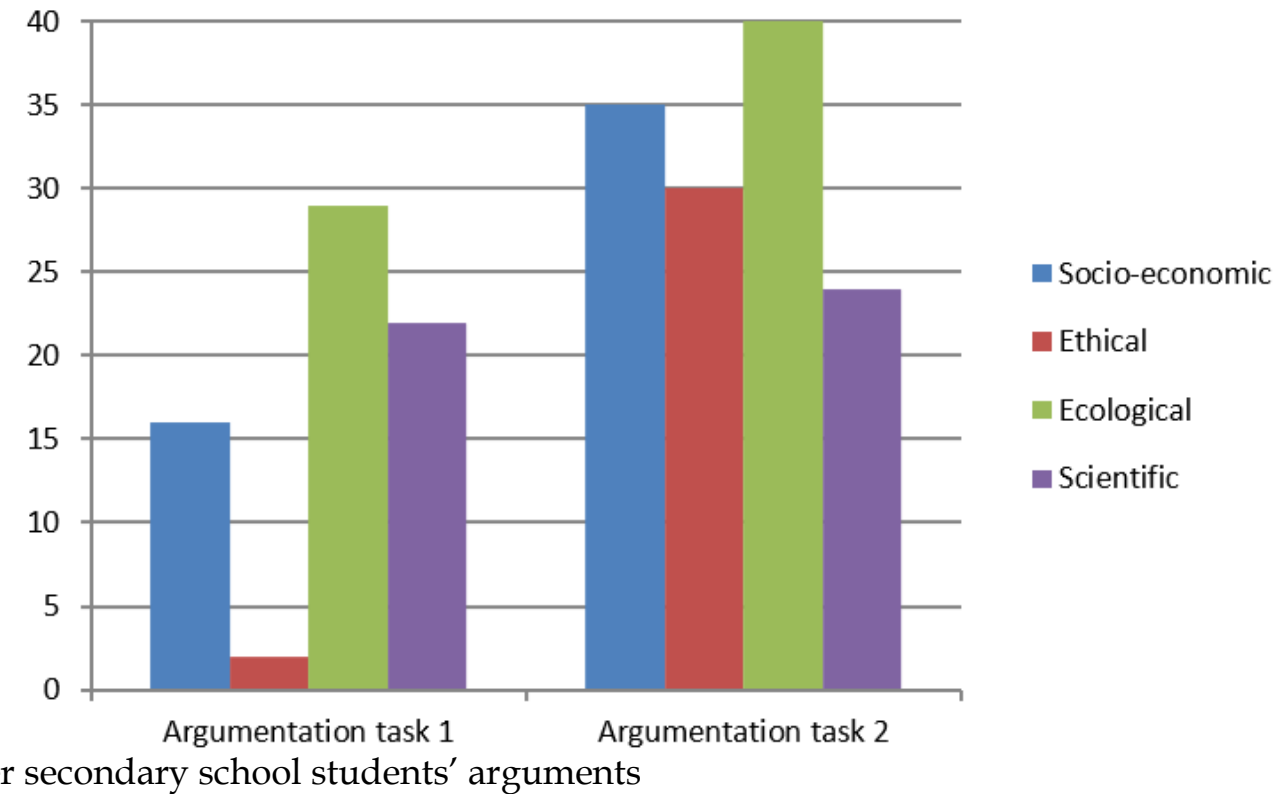

Figure 5. Upper secondary school students' arguments

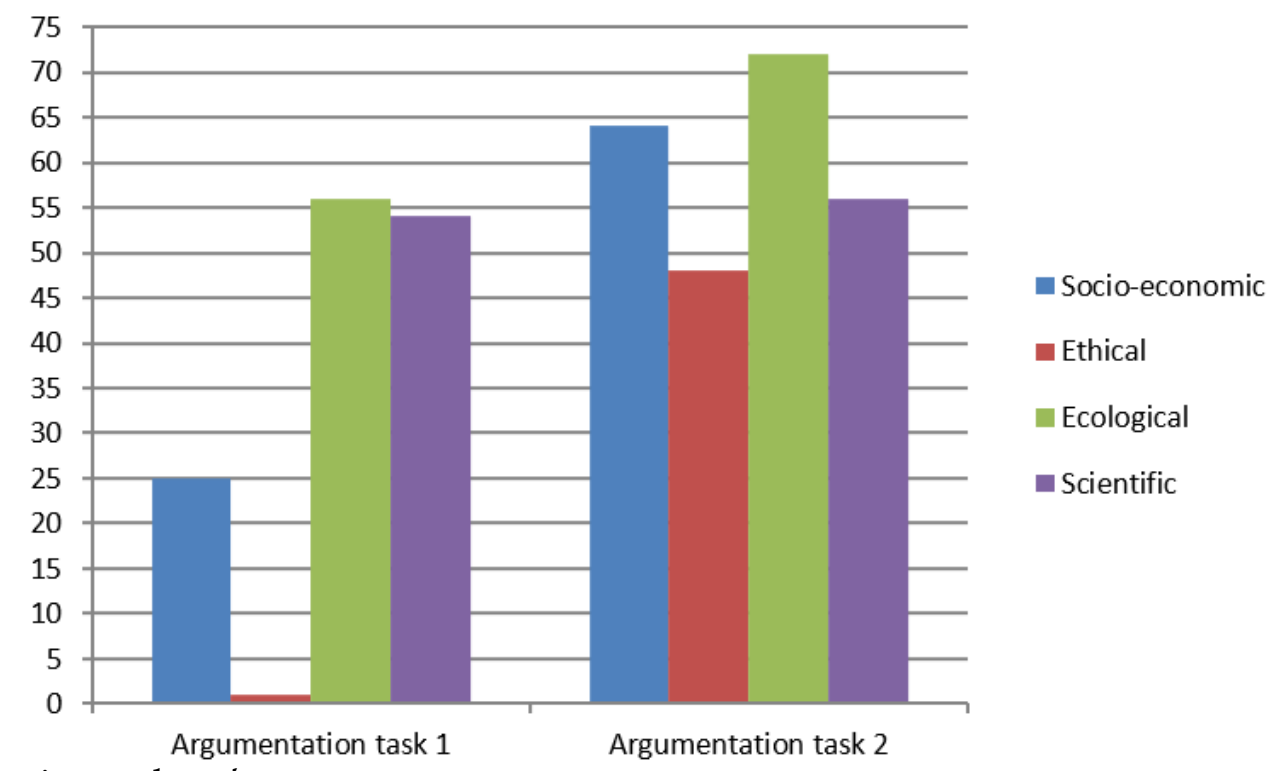

Figure 6. University students' arguments

arguments were mentioned most often by both groups in all of the tasks. Ethical arguments appeared least often the Argumentation task 1. Only 2 out of 40 upper secondary school and 1 out of 73 undergraduate students used ethical arguments. After the intervention, 30 upper secondary school and 48 undergraduate students began to use ethical arguments.

From the students' arguments, we can see that the controversial issue of pesticides use was viewed as close to the students' personal lives. One student said: "I live in a rural area and my father is a rice farmer. We have been using indigenous bio-pesticides from a plant extract, which is the legacy of our ancestors. It is more ecological-friendly and protects the fertility of the land." Connecting the sustainability issue to local experiences and multiple scientific worldviews seems to increase the students' interest in expressing their ideas more broadly. This can be seen from the rising number of students who expressed arguments in terms of socio-economic, ecological, and ethical arguments. This indicates that chemistry lessons including the local context of ISc can serve as a bridge for students to connect global issues to the knowledge they already possess. Students reconstruct more integrated knowledge about an issue using their experiences taken from multiple perspectives. Learning about complex socio-scientific issues requires a fundamental understanding of natural systems and the relationship between humans and the living and non-living environment (Colucci-Gray et al., 2006; Hogan, 2002). Therefore, research suggests considering multiple viewpoints when making decisions (Eisen et al., 2009; Zeidler et al., 2009).

Ecological arguments were the most often mentioned in both the first and in the second argumentation tasks. This result is not surprising, because the topic is closely related to environmental concerns. It seems that the 
students' initial view was mostly restricted to the risks of pesticides use on the environment. The majority of students connected the issue with environmental damage due to the use of synthetic pesticides. One person stated: "Currently, we are not required to use (dangerous) synthetic pesticides, because they present a high risk to the environment. If the use of synthetic pesticides is ongoing, it will cause new resistant strains of pests. Pests are difficult to stop and adversely affect the environment. The residue of pesticides in foodstuffs will cause disease and in the long term is harmful to health." The student tried to frame environmental concerns through a different point of view related to both ecology and the socio-economical aspect of health.

All tasks completed by the participants involved discussing the role of scientific technology. Both groups of students expressed a wide array of scientific arguments, which appeared in almost equal measures during the first and second argumentation tasks. This result is in stark contrast to other studies (Albe, 2008; Sadler \& Zeidler, 2005) in which students generally tended to involve less scientific knowledge in their arguments on ESD issues. The students in the current study linked their arguments to the development of scientific technology to solve the pesticides use problem, but they began to do so in a reflective manner. As one student stated: "We still need synthetic pesticides, because they are very helpful in eradicating crop pests for farmers. But we need to have effective and specific ways so that the risk of synthetic pesticide use can be reduced and not be widespread. For example, we could spray pesticides on target crops using drones so we don't have too much impact on wildlife, the environment and human health." The role of collaboration between WMSc and ISc was also considered. In this case, the knowledge claims were not compared to one another. Instead suggestions for collaboration were made to drive innovation: "In my opinion, we can combine the local wisdom of traditional knowledge in Indonesia with the technology offered by Western science in order to collaborate and produce natural pesticides that are durable, but do not damage the environment."

The level of socio-economic arguments increased in the post-intervention task. It appears that a discussion of the pros and cons of synthetic versus indigenous biopesticides can potentially encourage students to link the issue with socio-economic factors. One student argued that: "From an economic standpoint, the materials of indigenous pesticides (botanical pesticides) are easier to obtain from the garden and we do not need to spend a lot of money to produce this pesticide." Another student contrasted a socio-economic argument with a scientific explanation: "Indigenous bio-pesticides could become a candidate for green pesticides. Their advantages can minimize soil damage. These pesticides are cheaper, because in rural areas the ingredients are easy to obtain. However, such pesticides has the disadvantage of not being very selective in eradicating certain pests. The material tends to be volatile, so it should be applied in large quantities periodically."
There was a significant increase in the students' ethical arguments in the second argumentation task. After ISc perspectives were presented to complement WMSc views, students were encouraged to express their ethical arguments. It seems that they viewed cultural and philosophical values stemming from indigenous local wisdom as a new insight. This provoked further ethical considerations when making a decision. Two examples can illustrate this:

"The philosophical perspective and the values of an indigenous society should be considered, especially in terms of environmental ethics, where nature should be well maintained for present and future generations. Because, in fact, humans need nature and not the opposite. So we should care for nature in a way that doesn't pollute the environment by controlling the use of pesticides and using green pesticides."

"I think the indigenous perspective should be considered to provide ethical insight and guidance to Western knowledge. This perspective teaches humans to use pesticides wisely and not to kill insects excessively in order to maintain the natural balance and ecosystem. This is important because when insect populations are lost, no organisms are left to aid in the decomposition of carcasses or the pollination of flowers, so that the situation ultimately disrupts other ecosystems."

Based on both arguments above, indigenous perspectives also encouraged the learners to analyze moral and philosophical questions, such as whether insects should be destroyed to protect human crops. This discussion is closely related to the philosophical aspects of eco-reflexivity, wherein people participate in community decisions. This includes advocating factors which affect both living and non-living entities in the environment (Mueller, 2009). The current study seemed to support students' awareness that chemistry has complex interactions with both society and the environment.

The philosophy of ESD and SSI-based education emphasizes the societal and ethical dimensions of chemistry education in order to help learners more meaningfully participate in classroom practices (Burmeister et al., 2012; Zeidler \& Sadler, 2008). This includes the aspects of values and attitudes, which are related to the students' affective domain. These aspects can be developed and connected to an individual's sociocultural background. This allows the student to view facts from a cross-cultural viewpoint (Rundgren \& Rundgren, 2010). Cultural or sociological perspectives are areas of pedagogical importance which are central to SSI-based teaching. They underscore the necessity to view students as moral agents, who are intimately involved with their own cultural, natural, and technological environments (Zeidler et al., 2005).

\section{CONCLUSION AND IMPLICATIONS}

This study examined students' application of their chemistry content knowledge and arguments. By doing 
so we obtained insights into how the ESD pedagogical approach can function. Combining the topic of pesticide use with a multi-perspective approach based on different scientific worldviews can improve both of these two important scientific literacy goals. This study confirms previous evidence showing how science learning can be enriched by the ESD framework in order to improve students' argumentation skills (Burmeister \& Eilks, 2012; Juntunen \& Aksela, 2014b).

This case study provided students with opportunities to apply chemical content, which is closely related and relevant to their lives, in the context of ISc. In terms of applying chemical concepts, we found that the two groups of students engaged in real-world connections between chemistry and context-driven tasks. University students showed higher levels of understanding by providing explanations and linking concepts. Their high school counterparts generally tended to simply recall factual knowledge as an answer. It became quickly clear that teachers need to pay more attention to the existence of misconceptions. This is especially true if the students are unfamiliar with the problem-solving task or are asked to transfer chemical concepts from different chemistry sub-disciplines into a new context. For this reason, we suggest that basic chemistry content knowledge related to the context should be reinforced. Also, the relationship between students' current knowledge and the newly-provided information should be fostered through various forms of activities that encourage higher-order thinking skills (Akkuzu \& Uyulgan, 2016; Broman \& Parchmann, 2014).

In terms of argumentation, both upper secondary school and university students made large improvements in employing socio-economic, ecological, scientific and ethical arguments. This factor is crucial in developing learners' understanding of sustainability issues. It helps them in value-based decision-making processes both in their personal and professional lives, which in turn allows them to become critically-thinking, democratic-minded citizens. One promising aspect was that the intervention broadly fostered the level of ethical argumentation among the participants. This is also important, because it is uncommon for most students to pass ethical judgment on socio-scientific issues (Juntunen \& Aksela, 2014b). This case study revealed that the indigenous perspective in terms of knowledge, culture, and the philosophy of local wisdom can enhance and provide broader insights into students' ethical considerations concerning sustainability. This falls in line with the current discussion of eco-justice in science education (Mueller, 2009). It has been suggested that science teachers should encourage their students to have more connections to cultural knowledge and human relationships.

Teaching interventions based on ESD-oriented chemistry learning have existed for quite some time. The inclusion of multiple scientific worldviews seems to add to the effectiveness and relevance of teaching and learning chemistry. Learning chemistry from an authentic ESD context associated with different knowledge systems aids the learners in their efforts. They can better apply chemical concepts in a new context containing socio-scientific, cultural and philosophical aspects. The ability to apply chemical concepts showed differences among students at different educational levels. The successes observed, however, can be viewed as promising, considering the short time frame of the intervention and the complex nature of the topic studied. This approach mirrors the humanistic dimension of learning chemistry, which integrates aspects of culture into chemistry education (Mahaffy, 2006). Teaching about pesticides from a WMSc view (see e.g., Zowada et al., 2019) was enriched by its engagement with ISc. From this case study, we can see that indigenous phenomena can act as a bridge for students to link their local and regional environments with chemical content knowledge. This offers them an alternative perspective to the development of WMSc and its related technology. The study presented in this paper has provided a valuable insight for teachers, educational practitioners and policy makers on how this pedagogical approach provides a potential contribution to develop critical scientific literacy (Sjöström \& Eilks, 2018).

The current study is necessarily limited in scope. The tools employed describe students' ability to apply conceptual knowledge and to use arguments to describe the results. The study does not, however, describe the relationship between these two variables. Several studies (Sadler, 2004; Sadler \& Zeidler, 2005; Tytler et al., 2001) have found that understanding content knowledge is related to the quality of argumentation presented for socio-scientific issues (Sadler, 2004). However, there is no evidence suggesting that individuals with different levels of content knowledge relied on different modes of informal reasoning (rationalistic, emotional, and intuitive). Understanding the science content behind a controversial issue does not necessarily imply that the students will base their decisions on science content. As Sadler (2004) has already suggested, we support the idea that educators can use sustainability-oriented SSI instruction to encourage students to participate in meaningful learning regarding the science concepts behind these issues. This research is only employed two groups of students and one indigenous phenomenon. It is necessary to conduct further research based on different perspectives chosen from other cultures, knowledge areas, and backgrounds. Further research could integrate the discussion of indigenous phenomena to foster learners' procedural knowledge in green science laboratory activities. This includes green chemistry learning about valuable natural substances. It also covers processes from ISc that can be explored in school science or at the undergraduate level. 
Author contributions: All authors have sufficiently contributed to the study, and agreed with the results and conclusions.

Funding: We are grateful for the support given to the project by the Islamic Development Bank (IsDB) and the Indonesian Ministry of Education and Culture.

Declaration of interest: No conflict of interest is declared by authors.

\section{REFERENCES}

Akkuzu, N., \& Uyulgan, M. A. (2016). An epistemological inquiry into organic chemistry education: Exploration of undergraduate students' conceptual understanding of functional groups. Chemistry Education Research and Practice, 17(1), 3657. https:/ / doi.org/10.1039/c5rp00128e

Albe, V. (2008). When scientific knowledge, daily life experience, epistemological and social considerations intersect: Students' argumentation in group discussions on a socio-scientific Issue. Research in Science Education, 38(1), 67-90. https: / / doi.org/10.1007/s11165-007-9040-2

Broman, K., \& Parchmann, I. (2014). Students' application of chemical concepts when solving chemistry problems in different contexts. Chemistry Education Research and Practice, 15(4), 516-529. https://doi.org/10.1039/c4rp00051j

Burmeister, M., \& Eilks, I. (2012). An example of learning about plastics and their evaluation as a contribution to Education for Sustainable Development in secondary school chemistry teaching. Chemistry Education Research and Practice, 13(2), 93-102. https://doi.org/10.1039/C1RP90067F

Burmeister, M., Rauch, F., \& Eilks, I. (2012). Education for Sustainable Development (ESD) and chemistry education. Chemistry Education Research and Practice, 13(2), 59-68. https:/ / doi.org/10.1039/C1RP90060A

Colucci-Gray, L., Camino, E., Barbiero, G., \& Gray, D. (2006). From scientific literacy to sustainability literacy: An ecological framework for education. Science Education, 90(2), 227-252. https: / / doi.org/10.1002/sce.20109

Dori, Y. J., Tal, R. T., \& Tsaushu, M. (2003). Teaching biotechnology through case studies - Can we improve higher order thinking skills of nonscience majors? Science Education, 87(6), 767-793. https://doi.org/10.1002/sce.10081

Duis, J. M. (2011). Organic chemistry educators' perspectives on fundamental concepts and misconceptions: An exploratory study. Journal of Chemical Education, 88(3), 346-350. https:/ / doi.org/10.1021/ed1007266

Duit, R., Gropengießer H., \& Kattmann U. (2005). Towards science education that is relevant for improving practice: the model of educational reconstruction. In $\mathrm{H}$. Fischer (ed.), Developing standards in research on science education (pp. 1-9). Taylor \& Francis.

Eilks, I., Rauch, F., Ralle, B., \& Hofstein, A.. (2013). How to balance the chemistry curriculum between science and society. In I. Eilks \& A. Hofstein (Eds.). Teaching chemistry - A Studybook (pp. 1-36). Sense.

Eisen, A., Hall, A., Lee, T. S., \& Zupko, J. (2009). Teaching water: Connecting across disciplines and into daily life to address complex societal issues. College Teaching, 57(2), 99-104. https://doi.org/10.3200/ СТСH.57.2.99-104

Erduran S., Simon S., \& Osborne J., (2004). TAPping into argumentation: Developments in the application of Toulmin's argument pattern for studying science discourse. Science Education, 88(6), 915-933. https:/ / doi.org/10.1002/sce.20012

Erduran, S., Ozdem, Y., \& Park, J. Y. (2015). Research trends on argumentation in science education: a journal content analysis from 1998-2014. International Journal of STEM Education, 2(1), 1-12. https: / / doi.org/10.1186/s40594-015-0020-1

Henderleiter, J., Smart, R., Anderson, J., \& Elian, O. (2001). How do organic chemistry students understand and apply hydrogen bonding? Journal of Chemical Education, 78(8), 1126. https://doi.org/ 10.1021/ed078p1126

Hofstein, A., Eilks, I., \& Bybee, R. (2011). Societal issues and their importance for contemporary science education-a pedagogical justification and the stateof-the-art in Israel, Germany, and the USA. International Journal of Science and Mathematics Education, 9(6), 1459-1483. https:/ / doi.org/10.1007 /s10763-010-9273-9

Hogan, K. (2002). Small groups' ecological reasoning while making an environmental management decision. Journal of Research in Science Teaching, 39(4), 341-368. https:/ / doi.org/10.1002/tea.10025

Ideland, M. (2018). Science, coloniality, and "the Great Rationality Divide": How practices, places, and persons are culturally attached to one snother in cience education. Science $\mathcal{E}$ Education, 27(7-8), 783803. https://doi.org/10.1007/s11191-018-0006-8

Juntunen, M. K., \& Aksela, M. K. (2014a). Education for sustainable development in chemistry - challenges, possibilities and pedagogical models in Finland and elsewhere. Chemistry Education Research and Practice, 15(4), 488-500. https://doi.org/10.1039/ C4RP00128A

Juntunen, M. K., \& Aksela, M. K. (2014b). Improving students' argumentation skills through a product life-cycle analysis project in chemistry education. Chemistry Education Research and Practice, 15(4), 639 649. https:/ / doi.org/10.1039/c4rp00068d

Karpudewan, M., \& Roth, W. M. (2018). Changes in primary students' informal reasoning during an 
environment-related curriculum on socio-scientific issues. International Journal of Science and Mathematics Education, 16(3), 401-419. https:// doi.org/10.1007/s10763-016-9787-x

Khaddoor, R., Al-Amoush, S., \& Eilks, I. (2017). A comparative analysis of the intended curriculum and its presentation in 10th grade chemistry textbooks from seven Arabic countries. Chemistry Education Research and Practice, 18(2), 375-385. https://doi.org/10.1039/c6rp00186f

Lee, Y. C., \& Grace, M. (2012). Students' reasoning and decision making about a socioscientific issue: A cross-context comparison. Science Education, 96(5), 787-807. https:/ / doi.org/10.1002/sce.21021

Liu, S. Y., Lin, C. S., \& Tsai, C. C. (2011). College students' scientific epistemological views and thinking patterns in socioscientific decision making. Science Education, 95(3), 497-517. https:/ / doi.org/10.1002/ sce. 20422

Mahaffy, P. (2006). Moving chemistry education into 3D: A tetrahedral metaphor for understanding chemistry: Union carbide award for chemical education. Journal of Chemical Education, 83(1), 4955. https:// doi.org/10.1021/ed083p49

Marks, R., \& Eilks, I. (2009). Promoting scientific literacy using a sociocritical and problem-oriented approach to chemistry teaching: Concept, examples, experiences. International Journal of Environmental and Science Education, 4(3), 231-245.

Mayring, P. (2000). Qualitative content analysis. Forum Qualitative Social Research, 1. http://www.qualita tive-research.net/fqs

Mueller, M. P. (2009). Educational reflections on the "ecological crisis": Ecojustice, environmentalism, and sustainability. Science \& Education, 18(8), 10311056. https:// doi.org/10.1007/s11191-008-9179-x

Murray, J. J. (2015). Re-visioning science education in Canada: A new polar identity and purpose. Education Canada, 55(4). http://www.ceaace.ca/education-canada/article/re-visioningscience-education-Canada

Oulton, C., Dillon, J., \& Grace, M. M. (2004). Reconceptualizing the teaching of controversial issues. International Journal of Science Education, 26(4), 411-423. https://doi.org/10.1080/095006903 2000072746

Reid, N., \& Hassan, A. (2004). Ideas underpinning success in an introductory course in organic chemistry. University Chemistry Education, 8(2), 4051.

Roberts, D. A. (2007). Scientific literacy/Science literacy. In S. K. Abell \& N. G. Lederman (Eds.), Handbook of research on science education (pp. 729-280). Lawrence Erlbaum.
Roberts, D. A. (2011). Competing visions of scientific literacy: The influence of a science curriculum policy image. In C. Linder, L. Ostman, D.A. Roberts, P. Wickman, G. Erickson, \& A. MacKinnon (Eds.), Promoting scientific literacy: Science education research in transaction (pp. 11-27). Routledge/Taylor \& Francis Group.

Rundgren, C. J., Eriksson, M., \& Rundgren, S. N. C. (2016). Investigating the intertwinement of knowledge, value, and experience of upper secondary students' argumentation concerning socioscientific issues. Science \& Education, 25(9-10), 1049-1071. https://doi.org/10.1007/s11191-0169859-x

Rundgren, S. N. C., \& Rundgren, C. J. (2010). SEE-SEP: From a separate to a holistic view of socioscientific issues. Asia-Pacific Forum on Science Learning and Teaching, 11(1), 1-24.

Sadler, T. D. (2004). Informal reasoning regarding socioscientific issues: A critical review of research. Journal of Research in Science Teaching, 41(5), 513-536. https:// doi.org/10.1002/tea.20009

Sadler, T. D., \& Zeidler, D. L. (2005). The significance of content knowledge for informal reasoning regarding socioscientific issues: Applying genetics knowledge to genetic engineering issues. Science Education, 89(1), 71-93. https://doi.org/10.1002/ sce. 20023

Simonneaux, L. (2014). Questions socialement vives and socio-scientific issues: New trends of research to meet the training needs of postmodern society. In C. Bruguiere, A. Tiberghien, \& P. Clement (Eds.), Topics and trends in current science education (pp. 3754). Springer. https:/ / doi.org/10.1007/978-94-0077281-6_3

Sjöström, J. \& Eilks, I. (2018), Reconsidering Different Visions of Scientific Literacy and Science Education Based on the Concept of Bildung. In Y. J. Dori, Z. R. Mavarech, \& D. R. Baker (Eds.), Cognition, metacognition, and culture in STEM education (pp. 6588). Springer. https://doi.org/10.1007/978-3-31966659-4_4

Sjöström, J., Eilks, I., \& Zuin, V. G. (2016). Towards ecoreflexive science education: A critical reflection about educational implications of Green Chemistry. Science \& Education, 25(3-4), 321-341. https:// doi.org/10.1007/s11191-016-9818-6

Snively, G., \& Williams, W. L. (2016). Knowing home: Braiding indigenous science with Western science (Book 1). University of Victoria.

Stuckey, M., Hofstein, A., Mamlok-Naaman, R., \& Eilks, I. (2013). The meaning of "relevance" in science education and its implications for the science curriculum. Studies in Science Education, 49(1), 1-34. https://doi.org/10.1080/03057267.2013.802463 
Tytler, R., Duggan, S., \& Gott, R. (2001). Dimensions of evidence, the public understanding of science and science education. International Journal of Science Education, 23(8), 815-832. https:/ / doi.org/10.1080/ 09500690010016058

Wiyarsi, A., \& Çalik, M. (2019). Revisiting the scientific habits of mind scale for socio-scientific issues in the Indonesian context. International Journal of Science Education, 41(17), 2430-2447. https://doi.org/ $10.1080 / 09500693.2019 .1683912$

Zeidler, D. L., \& Sadler, T. D. (2008). Social and ethical issues in science education: A prelude to action. Science $\mathcal{E}$ Education, 17(8-9), 799-803. https:/ / doi.org/10.1007/s11191-007-9130-6

Zeidler, D. L., Sadler, T. D., Applebaum, S., \& Callahan, B. E. (2009). Advancing reflective judgment through socioscientific issues. Journal of Research in Science Teaching, 46(1), 74-101. https://doi.org/ 10.1002/tea.20281

Zeidler, D. L., Sadler, T. D., Simmons, M. L., \& Howes, E. V. (2005). Beyond STS: A research-based framework for socioscientific issues education. Science Education, 89(3), 357-377. https://doi.org/ $10.1002 /$ sce. 20048

Zidny, R., \& Eilks, I. (2020). Integrating perspectives from indigenous knowledge and Western science in secondary and higher chemistry learning to contribute to sustainability education. Sustainable
Chemistry and Pharmacy, 16, 100229. https://doi.org/10.1016/j.scp.2020.100229

Zidny, R., Sjöström, J., \& Eilks, I. (2020). A multiperspective reflection on how indigenous knowledge and related ideas can improve science education for sustainability. Science $\mathcal{E}$ Education, 29(1), 145-185. https://doi.org/10.1007/s11191019-00100-x

Zohar A., \& Dori Y. J., (2003), Higher order thinking kills and low-achieving students: Are they mutually exclusive?. The Journal of the Learning Sciences, 12(2), 145-181. https://doi.org/10.1207/S15327809JLS12 02_1

Zohar, A. (2004). Higher order thinking in science classrooms: Students' learning and teachers' professional development. Kluwer. https://doi.org/ 10.1007/978-1-4020-1854-1

Zowada, C., Frerichs, N., Zuin, V. G., \& Eilks, I. (2019). Developing a lesson plan on conventional and green pesticides in chemistry education - a project of participatory action research. Chemistry Education Research and Practice, 21, 141-153. https://doi.org/10.1039/c9rp00128j

Zowada, C., Gulacar, O., \& Eilks, I. (2018). Incorporating a web-based hydraulic fracturing module in general chemistry as a socio-scientific issue that engages students. Journal of Chemical Education, 95(4), 553559. https:/ / doi.org/10.1021/acs.jchemed.7b00613

\section{http://www.ejmste.com}

